\title{
Nigella sativa (Black Seed) as a Natural Remedy against Viruses
}

\author{
Rasha Saleh Basurra ${ }^{1,2} \mathbb{D}$, Seok Mui Wang ${ }^{3,4} \mathbb{D}$ and \\ Mohammed Abdelfatah Alhoot ${ }^{5 *}$
}

${ }^{1}$ Post Graduate Centre (PGC), Management \& Science University (MSU), Shah Alam, Selangor, Malaysia. ${ }^{2}$ Department of Paraclinic, Faculty of Medicine \& Health Science, University of Aden, Aden, Yemen.

${ }^{3}$ Department of Medical Microbiology \& Parasitology, Faculty of Medicine, Universiti Teknologi MARA, Selangor, Malaysia.

${ }^{4}$ Institute of Pathology, Laboratory and Forensic Medicine (I-PPerForM), Universiti Teknologi MARA, Selangor, Malaysia.

${ }^{5}$ International Medical School (IMS), Management \& Science University (MSU), Shah Alam, Selangor, Malaysia.

\begin{abstract}
The currently available antiviral agents are associated with serious adverse effects, coupled with the increasing rate of viral resistance to the existing antiviral drugs. Hence, the search for alternative natural remedies is gaining momentum across the globe. Nigella sativa Linnen, also called black seed, is a medicinal plant that is gaining worldwide recognition and has been extensively investigated. The present work is aimed to review the existing literature on the antiviral efficacy of Nigella sativa extracts (oil and bioactive compounds). The findings reveal that numerous articles have been published on Nigella sativa and its beneficial effects against different kinds of diseases. However, the antiviral efficacy of Nigella sativa is yet to be given the proper research attention it deserves.
\end{abstract}

Keywords: Nigella sativa, Black seed, Antiviral activity, Viruses, Natural remedy

*Correspondence: malhoot@hotmail.com; +6035510 6868

(Received: November 05, 2020; accepted: January 20, 2021)

Citation: Basurra RS, Wang SM, Alhoot MA. Nigella sativa (Black Seed) as a Natural Remedy against Viruses. J Pure Appl Microbiol. 2021;15(1):29-41. doi:10.22207/JPAM.15.1.26

(C) The Author(s) 2021. Open Access. This article is distributed under the terms of the Creative Commons Attribution 4.0 International License which permits unrestricted use, sharing, distribution, and reproduction in any medium, provided you give appropriate credit to the original author(s) and the source, provide a link to the Creative Commons license, and indicate if changes were made. 


\section{INTRODUCTION}

For a long time, viruses have been considered the most common pathogen to human; the last decades have witnessed outbreaks of various viral diseases, such as smallpox, an influenza pandemic (Spanish flu), the HIV/AIDS epidemic, and the ongoing Coronaviruses which have caused serious harm and public health threat globally (De Clercq, 2004; Wang, Wang, \& Guan, 2012; Chen et al., 2020; Trilla, Trilla, \& Daer, 2018; World Health organization, 2019; WHO, 2017b). For this reason, various antiviral agents have been recommended for clinical use, with the number of approved antiviral agents significantly increasing to around 37 (De Clercq, 2004). Regardless of these, the drug efficacy, toxicity, and cost of these drugs remain a challenge in the developing countries where viral infections are predominant (AbdelMoneim et al, 2013; Kitazato, Wang, \& Kobayashi, 2007; Vermani \& Garg, 2002). Therefore, there is a shift towards finding more natural remedies to be considered as alternative medicinal choices to reduce and control the negative side effects of the conventional antiviral drugs; the natural remedies have been sought to serve as effective treatment options for viral infections at a lower cost (Agha, Ahmad, Islam, Gill, \& Athar, 2010).

Natural products (herbs) have been used as traditional medicine for several decades. They have been extensively studied due to their vital role in managing human illness even though their safety and effectiveness are yet to be scientifically verified. According to the World Health Organization (WHO), up to $80 \%$ of the global population still relies on alternative therapy for their health (Farnsworth, Akerele, Bingel, Soejarto, \& Guo, 1985). Different plant species, such as Zingiber capitatum, seaweed, green tea, and curcumin, have been evaluated for antiviral efficacy (Lin, Hsu, \& Lin, 2014). Nigella sativa is one of these natural plants that have been previously documented to possess various medicinal activities, such as antibacterial, antidiabetic, anti-inflammatory, antioxidant, antifungal, anticancer, and antiviral activities (Ahmad et al., 2013; Yimer et al., 2019). Furthermore, some studies compared the effectiveness of Nigella sativa with other natural products. The antiviral and antioxidant activity of some herbal extracts including Nigella sativa had been evaluated by
(Dorra, El-Berrawy, Sallam, \& Mahmoud, 2019). In term of antiviral activity against influenza virus (H5N1), the study found that Nigella sativa (black seed) has a higher percentage of inhibition value at the maximum non-cytotoxic concentration when compared to Zingiber officcinale (Ginger), meanwhile in term of antioxidant activity all plant extracts exhibited a good antioxidant activity, however Nigella sativa extract exhibited a higher antioxidant activity than Foeniculum vulgare (Fennel). Moreover, crude and diluted extracts of Nigella sativa and Zizyphus spina-christi Mill plant have been compared for their inhibition effect against broad bean mottle virus (BBMV) on Chenopodium amaranticolor as a local lesion host for the virus. Crude extract of Nigella sativa proved to be more effective than the diluted extract in inhibiting the local lesions produced by (BBMV) when compared to the Zizyphus plant extracts (E. F. Mohamed, 2011). Ibrahim et al., 2017 examined water soluble extracts of black cumin (Nigella sativa) along with other natural spices products such as turmeric (Curcuma longa), black pepper (Piper nigrum), cardamom (Elettaria cardamomum) and aniseed (Pimpinella anisum) for their effect on the growth of pathogenic strains such as Aspergillus parasiticus strains and ability to produce aflatoxin contamination. The study found that black cumin has a moderate antifungal activity but it has a high potential to inhibit and control the production of aflatoxin contamination that is considered to be one of the most toxic substances that fungi produce after fungal infection. Sangi et al., 2018 compared the antihyperglycemic effect of some plants including black seed (Nigella sativa), mushroom (Pleurotus ostreatus), and ginger (Zingiber officinale) with metformin. The study has found that Nigella sativa and ginger have an effect in decreasing the serum glucose levels when compared to metformin and have the ability to regenerate pancreatic beta islets of Langerhans in the pancreas, while other plants such as mushroom can decrease the serum glucose levels but it does not have the ability to regenerate pancreatic beta cells.

However, despite the vast number of published articles on Nigella sativa, a review of its antiviral activity has yet to be conducted to date. Therefore, this paper aims to fill this gap by conducting a narrative review of the literature 
on the antiviral efficacy of the extracts, oil and bioactive compounds of Nigella sativa against viruses. Although Nigella sativa as a natural remedy has been widely used as an alternative method for the treatment against viruses, it is still necessary to evaluate which therapeutic method and/or which compounds of Nigella sativa is effective in the treatment against viruses by reviewing the available literature which will provide data to determine the suitable combinations of therapeutic methods and compounds that might give great promise in finding a suitable remedy against viruses. In this way, the current study contributes to the Nigella sativa literature by identifying the aspects of its efficacy that needs to be experimentally evaluated. Nigella sativa Overview

One of the traditional herbal medicines that are currently gaining worldwide recognition and research attention is Nigella sativa $L$. This plant has been described as the Miracle Herb of the Century (Goreja, 2003), and known globally by different local names; for instance, the Arabian and Muslim community refer to this plant as Habbat Al-barakah, Al-habahat Alsawda, and Al-kamoun Alaswad while English speakers called it black cumin, black caraway or black seed (Zohary, Hopf, \& Weiss, 2012)

Nigella sativa belongs to the family Ranunculaceae; it can grow up to $20-90 \mathrm{~cm}$ tall. It is a small flowering plant with finely divided leaves. It produces flowers (with 10 petals) of different shades, ranging from white and yellow to pink, blue and purple. Previous studies have reported the presence of various bioactive compounds from Nigella sativa, especially thymoquinone (TQ) which is the most essential bioactive compound in Nigella sativa, accounting for about $30-48 \%$ of the total bioactive compounds of Nigella sativa. Among the other reported bioactive compounds of Nigella sativa oil are carvacrol (6\%-12\%), thymohydroquinone $(30 \%-40 \%)$, p-cymene $(7 \%$ $15 \%)$, dithymoquinone, 4-terpineol (2\%-7\%), sesquiterpene longifolene (1\%-8\%), t-anethol (1\%-4\%), $\alpha$-pinene, thymol, etc. (Ahmad et al., 2013; Asif et al., 2015; Houghton, Zarka, B., \& Hoult, 1995). However, the most studied bioactive component of Nigella sativa oil is TQ owing to its numerous therapeutic properties (Woo, Kumar, Sethi, \& Tan, 2012; Torequl Islam et al., 2016;
Schneider-Stock, et al., 2014). Table 1 summarizes some important findings of TQ studies.

Both the essential oil and crude extract of Nigella sativa have proven and been reported to have several medicinal properties, such as antidiabetic (al-Awadi, Fatania, \& Shamte, 1991), anticancer (M. A. Randhawa \& Alghamdi, 2011), anti-inflammatory (Houghton et al., 1995), immunomodulatory (Mohamed Labib Salem, 2005) antioxidant (Meral, Yener, Kahraman, \& Mert, 2001), antimicrobial (Randhawa, Alenazy, Alrowaili, \& Basha, 2017), analgesic (Hajhashemi, Ghannadi, \& Jafarabadi, 2004), cardiovascular disorders (Zaoui et al., 2002), antifungal (Elfadil, Fahal, Kloezen, Ahmed, \& van de Sande, 2015), antiparasitic (Fattahi Bafghi, Vahidi, Anvari, Barzegar, \& Ghafourzadeh, 2011), neurotoxicity (Khazdair, 2015), antinociceptive (Khazdair, 2015), antimalarial (Khazdair, 2015), and antiviral activities (Salem \& Hossain, 2000).

\section{Limitations of Nigella sativa}

Despite all the pharmaco-therapeutics effects of Nigella sativa, some limitations of its usage and production raised during the clinical investigations that can limit its usage and clinical development. Some studies reported mild side effects of Nigella sativa when it was given as a treatment for certain diseases. Nausea, bloating, and burning sensation were observed when functional dyspeptic patients have been given 5 $\mathrm{mL}$ of Nigella sativa oil mixed with honey orally daily. These results were reported when this study evaluated the efficacy and safety of this mixture to have a gastro-protective and anti $\mathrm{H}$. pylori activity. (Mohtashami et al., 2015). Other studies that examined Nigella sativa seeds on patients suffering from seasonal allergic rhinitis reported that use of Nigella sativa was effective in mild and moderate allergic rhinitis symptoms reduction, however adverse effects such as nasal dryness and diarrhea were observed in some patients, which are consider minor effects when compared with conventional drugs used for allergic rhinitis (Akhtar, 2016; A. Mohamed, Abdul, \& Ahmed Alobaidi, 2012). In another study by Dogar et al., (2009) side effects such as pancreatitis, hyperbilirubinemia, diabetes mellitus, diarrhea and hypofibrinogenemia appeared when children with acute lymphoblastic leukemia were treated with L-asparaginase, while none of these serious 
effects were observed in patients who received conventional treatment with Nigella sativa seeds in a powder form. However, the study concluded that low side effects associated with the consumptions Nigella sativa seeds were significantly less when compared to conventional therapy and the use of L-asparaginase, thus Nigella sativa has high beneficial properties as an anti-cancer agent if given in combination with other cytotoxic drugs. Some studies link these limitations of Nigella sativa and any herbal medicine to the short duration of treatment, loss to follow-up, small sample size and participants' preferences of herb use form (Akhondian et al., 2011; Griffin \& Citkovitz, 2017; Rizka, Setiati, Lydia, \& Dewiasty, 2017).

On the other hand, Nigella sativa has a number of limitations regarding its productions. TQ has been reported that it has limited bioavailability and exhibits light and heat sensitivity (Goyal et al., 2017). In addition, TQ is considered as a compound that has a rapid distribution and elimination from plasma when given via intravenous administration, while has relatively slower absorption after oral administration using a rabbit as an animal model (Alkharfy, Ahmad, Khan, \& Al-Shagha, 2015). Another limitation reported by Mohammed et al., (2018) was poor water solubility. This limitation is closely linked to the different polarity of the oil and water that directly led to poor bioavailability due to decrease in the absorption rate in the gastrointestinal tract.

To prove safe usage and a good production of Nigella sativa, many efforts need to be undertaken to eliminate these limitations. Therefore, further clinical trials, experimental investigations, drug development and animal studies are required to address these limitations and enhance the therapeutics effects of Nigella sativa.

\section{Antiviral Activity of Nigella sativa Nigella sativa against Herpesviruses}

The antiviral efficacy of Nigella sativa and TQ against herpesviruses has been well documented. Herpesviridae is a big family of DNA viruses known to cause various diseases in humans and animals; herpesviruses are a common member of this family, with the $\alpha$-herpesviruses being the most common subfamily. Herpesviruses are classified into herpes simplex viruses 1 and 2 (HSV-1, HSV-2), with HSV-1 being the cause of mouth ulcers while genital ulcers are caused by HSV-2, even though HSV-1 has been implicated in genital infections (Van Lint \& Knipe, 2019). In 2012, the WHO estimated that about 3,709 million people globally had prevalent HSV-1 infection (67\% global prevalence), while HSV-2 infection was estimated in 417 million people $(11.3 \%$ global prevalence) (Looker et al., 2015). Numerous studies have observed that HSV can be treated with natural products like aloe vera (Rezazadeh, Moshaverinia, Motamedifar, \& Alyaseri, 2016), seaweed species (H. Wang, Ooi, \& Ang, 2008), and sandalwood oil (Benencia \& Courreges, 1999). One study investigated the antiviral activity of Nigella sativa against HSV-1 and HSV-2 and found that Nigella sativa had a toxic effect on the host cell but showed a slight antiviral activity against HSV-1 (with an $\mathrm{IC}_{50}$ value of around $50 \mu \mathrm{g} / \mathrm{mL}$ against HSV-2) (Sokmen, 2001). Cytomegalovirus (CMV) is another highly prevalent member of the Herpesviridae. Murine cytomegalovirus (MCMV) is a $\beta$-herpesvirus that is associated with fatal and disseminated infections in immunocompromised animals; it is similar to the human cytomegalovirus that causes infections in immunodeficient persons. Nigella sativa oil has been reported to completely inhibit the viral load in the spleen and liver against MCMV infection (M L Salem \& Hossain, 2000). Besides HSV and MCMV, Epstein-Barr virus (EBV), a human virus that belongs to the $\gamma$-herpesvirus family, also been studied (Zihlif et al., 2013). Avian Infectious Laryngotracheitis virus (ILTV) is caused by $\alpha$-herpesviruses while the Gallid herpesvirus 1 species are responsible for respiratory disease in chickens and pheasants (Ou \& Giambrone, 2012); both have been used to test for the antiviral activity of black seed extracts (Zaher, Ahmed, \& Zerizer, 2008). The study showed that Nigella sativa inhibited the activity of ILTV at the concentration of $35 \mu \mathrm{M}$; this result was supported by the previous observations on the antiviral effect of Nigella sativa which linked the observed activity to TQ, the main bioactive compound of Nigella sativa with reported antimicrobial effect against various fungi, viruses, and bacteria (M. Randhawa et al., 2017).

Nigella sativa against human immunodeficiency virus

Human immunodeficiency virus (HIV) infection is still considered the most global public 


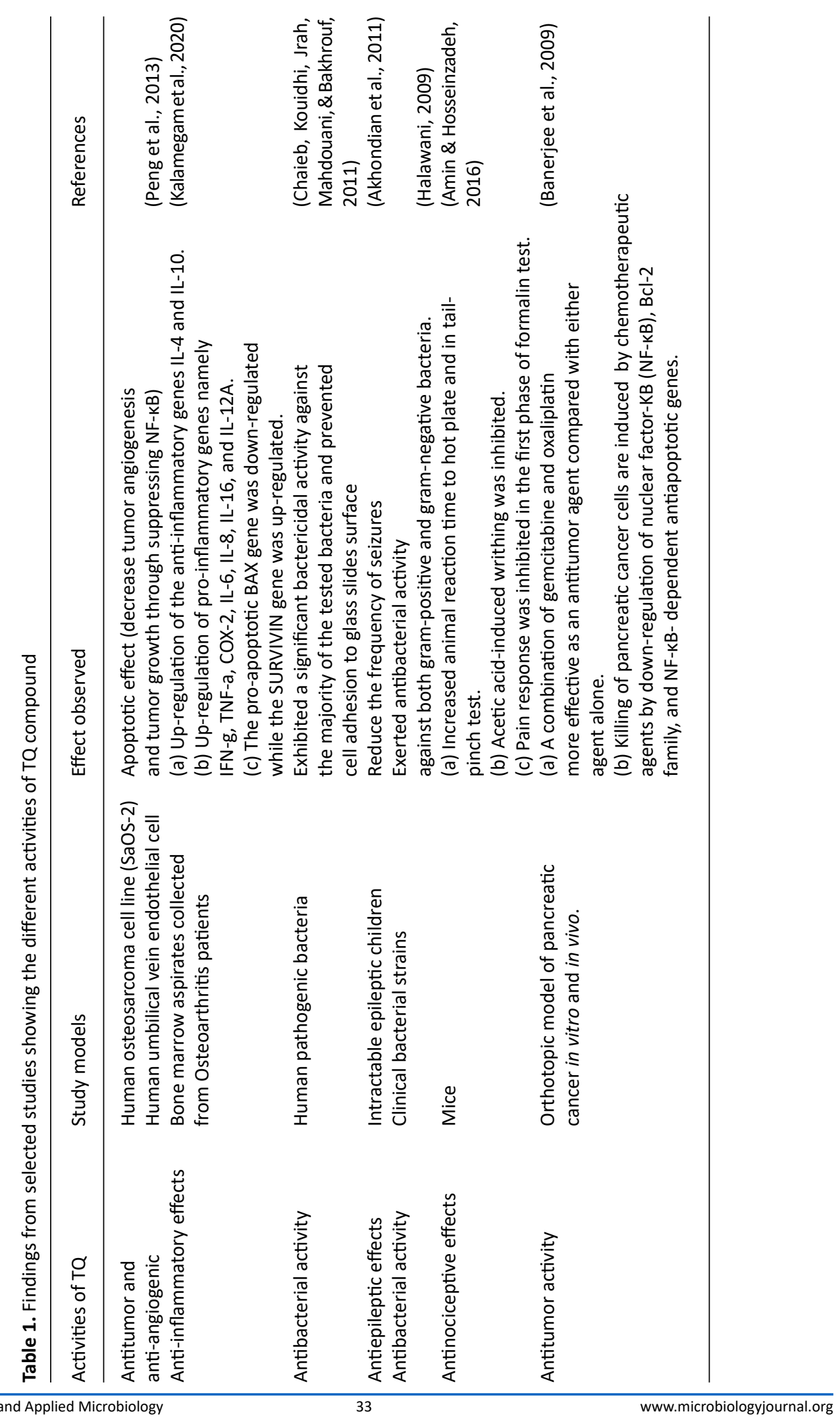


health problem. The WHO report of November 2019 (WHO, 2019) showed that more than 32 million lives have been lost to HIV since it was first reported in 1981 (UNAIDS, 2006). Globally, approximately 37.9 million people were estimated to be living with HIV at the end of 2018 (World Health Organization, 2019). HIV is classified into the genus Lentivirus and belongs to the family of Retroviridae. Persons infected with HIV can gradually develop acquired immunodeficiency syndrome (AIDS) which is the terminal stage of HIV infection. HIV attacks the CD4 cells of the body, thereby weakening the immune system. This makes it hard to recover from simple infections that healthy people can easily fight off. After HIV infection, a person can live with the virus for about 2 to 15 years based on individual differences before progressing to the terminal phase that manifests as AIDS (WHO, 2019).

To date, there is no preventive vaccine or completely effective treatment against HIV. Recently, Onifade and his colleagues conducted several studies on the efficacy of a mixture of Nigella sativa and pure honey extracts to treat some HIV patients. They reported a wide range of activity against HIV via direct reduction of the viral load and/or increase of the CD4 count (Onifade et al., 2013; Onifade et al., 2011; Onifade \& Jewell, 2012; Onifade A. A., Jewell A.P., Okesina, 2011, 2015; Onifade A.A., Jewell A.P., 2013; Onifade A.A., 2014).

\section{Nigella sativa against Hepatitis $\mathrm{C}$ virus}

As per the WHO, approximately 71 million people were infected by the Hepatitis $C$ virus (HCV) in 2015; hence, Hepatitis $C$ is seen as a global public health issue that is mainly characterized by the high level of liver enzyme expression. These enzymes are the most obvious signs of hepatic injury because their cytoplasmic level normally increases following liver injury (Hajarizadeh, Grebely, \& Dore, 2013. Egypt is one of the countries in the world with a high prevalence rate of $\mathrm{HCV}$ based on the morbidity and mortality rates; the highest prevalence percentage was reported in 2013 with around $10-15 \%$ out of the general population of Egypt as per reported by Abdel-Moneim et al. (2013) and Barakat, El Wakeel, \& Hagag (2013). Both studies consistently proved that Nigella sativa seed oil significantly decreased the viral load and reduced the level of liver enzymes expression among the studied Egyptian HCV patients. Administration of Nigella sativa extract significantly increased the serum levels of total protein and albumin post-treatment, showing an improvement in clinical condition. The results of these two studies were in agreement with other studies that have shown similar effects in animals treated with Nigella sativa (al-Gaby, 1998; Shewita \& Taha, 2011; Tollba, 2003). These results may be due to the hepatoprotective effects of the TQ content of Nigella sativa as having been reported by many studies (El-Dakhakhny, Mady, Lembert, \& Ammon, 2002; Mansour, 2000). Although both studies used different extracts, such as seed oil extract and ethanolic extracts of Nigella sativa, they revealed that Nigella sativa is a safe extract that reduced the viral load and improved the clinical condition of the patients.

On the other hand, the outcome of a study (Oyero et al., 2016) showed that Alpha-zam $(\alpha-Z a m)$ can be used as a selective inhibitor of HCV replication. $\alpha$-Zam, as per previous studies, has a combined formula of a herbal remedy containing $60 \%$ Nigella sativa and $40 \%$ freshly harvested pure honey as the major constituents (Onifade et al., 2011; Onifade A.A., Jewell A.P., 2013; Onifade A.A., Jewell A.P., Okesina, 2011).

\section{Nigella sativa against Newcastle disease}

Newcastle disease virus (NDV) infects different bird species globally, causing severe losses to farmers (Cattoli, Susta, Terregino, \& Brown, 2011). Studies have reported positive effects of Nigella sativa oil, seeds, and other extracts on broilers in the form of improved growth performance when used as a dietary component (Durrani et al., 2007; Kumar \& Patra, 2017; Shewita \& Taha, 2011; Toghyani, Toghyani, Gheisari, Ghalamkari, \& Mohammadrezaei, 2010). Other studies have also reported positive effects of Nigella sativa on the immune responses of poultry (Khan, Anjum, Parveen, Khawaja, \& Ashraf, 2013; Yaseen, 2003). These findings were corroborated by A. U. Khan et al., (2018) who also observed a notable reduction in the mortality rate in embryonated chicken eggs, showing the ability of ethanolic extract of Nigella sativa to enhance immunity and decrease viral load against NDV.

Nigella sativa against Peste des petits Ruminants Virus

Peste des petits Ruminants Virus (PPRV) 
causes a serious viral infection of the respiratory system and gastrointestinal tract of animals, thereby producing high annual morbidity and mortality (Balamurugan, Hemadri, Gajendragad, Singh, \& Rahman, 2014). Even though antiviral drugs and vaccination can control the spread of the virus, the use of herbal products against PPRV has been studied and proved to have similar effects as some antiviral drugs (T.C. \& G., 2012; Wosu, 1989). Nigella sativa also has in vivo effect against PPRV in goats fed with Nigella sativa seeds and in vitro when infected cell lines were treated with Nigella sativa alcoholic extract (K. Aqil et al., 2017; Kiran Aqil et al., 2018). Nigella sativa showed significant antiviral activity against PPRV by decreasing the liver enzyme levels after treatment (Abdel-Moneim et al., 2013; Barakat, El Wakeel, \& Hagag, 2013). This has been linked to the protective action of Nigella sativa due to the bioactivity of its components (Adam et al., 2016; Mohideen, Ilavarasan, Sasikala, \& Thirumalai Kumaran, 2003). However, Kiran Aqil et al., (2018) described a suppressing activity of Nigella sativa against PPRV via increasing cell survival percentage and reducing the pathogenic effects of infected goats.

\section{Nigella sativa against Coronaviruses}

Coronavirus was first described in 1931

by Dr. Oskar Seifried, a veterinarian, as a serious threat to animal health (Seifried, 1931). However, it was re-identified in the 1960s as a group of viruses that can cause both animal and human infections (Kahn \& Mclntosh, 2005). Coronavirus is a positive-sense enveloped single-stranded-RNA virus of the Coronaviridae family; it is classified into 4 recognized genera which are alpha, beta, gamma, and delta coronaviruses (Nakagawa, Lokugamage, \& Makino, 2016). The members of the Coronavirus family are normally implicated in enteric and upper respiratory tract infections in humans and other animal species (Weiss \& Navas-Martin, 2005). In most humans, it mainly causes mild infections of the upper respiratory tract. To date, there are seven identified human coronaviruses; these are 229E, NL63, OC43, HKU1, MERS-CoV, SARS-CoV, and SARS-CoV-2 (or COVID-19) (Geller, Varbanov, \& Duval, 2012; Marty \& Jones, 2020; Weiss \& Navas-Martin, 2005). Coronaviruses have been the major cause of several global epidemics with high mortality; the first coronavirus-related epidemic,
SARS, in 2002-2003, affected more than 8,000 persons with over 700 deaths (Anthony R. Fehr, \& Stanley Perlman, 2015). In 2012, another novel human coronavirus infection called MERS-CoV or MERS was reported in the Middle East, causing respiratory tract infections mainly in the Middle East; MERS affected about 2,206 person while 787 deaths were recorded (Fehr et al., 2015). The ongoing COVID-19 is the latest coronavirus-related infection; it has affected more people than SARS or MERS within a shorter period (Marty \& Jones, 2020). Nigella sativa is used for the treatment of respiratory diseases like chest congestion, shortness of breath, bronchospasm, and asthma in folk medicine (Goreja, 2003), while its bioactive compounds are used in pharmacological studies as effective ingredients to prepare drugs (Ahmad et al., 2013).

Nigella sativa extract has been evaluated for its efficacy in preventing the replication of coronavirus (CoV) during active coronavirus infection; the extracts successfully reduced the virus loads in the treated cases (Ulasli et al., 2014). Even though previous studies on the antiviral efficacy of Nigella sativa have shown significant results, the effect of the crude ethanol extract of Nigella sativa against the Avian infectious bronchitis virus (IBV) remains unclear. IBV is a gamma coronavirus that causes upper respiratory tract infection in birds, causing the laying of eggs with weakened and deformed shells. (C. Chen et al., 2014) found that Nigella sativa extract had no significant impact on the virus titres as it failed to inhibit IBV replication when compared to the control.

\section{Nigella sativa against Influenza virus}

Influenza viruses belong to the Orthomyxoviridae family; this family can be subgrouped into A, B, and C. They are implicated in most cases of respiratory tract infections that manifest in fever, headache, sneezing, muscle pains, sore throat, and joint pains; more severe conditions, such as pneumonia, are also associated with influenza virus infection (Blumel et al., 2009; Eccles, 2005). Influenza virus infection has been considered the most devastating epidemic that caused the highest mortality in humans. In 1918, the influenza A virus pandemic (Spanish flu) caused the death of approximately 40 to 50 million people (Trilla, Trilla, \& Daer, 2008). Avian influenza A virus 
(AIVs), called bird flu, is classified into subtypes based on different combinations of various viral surface proteins (such as hemagglutinin (HA) and neuraminidase (NA)). Several studies tested the effect of Nigella sativa on subtypes H9N2 and H5N2 against AIVs subtypes and found active inhibition of virus replication, enhanced immune response, and suppression of viral pathogenicity in poultry (Dorra et al., 2019; Mady, Arafa, Hussein, Aly, \& Madbouly, 2013; S. Umar et al., 2016; Sajid Umar, Munir, et al., 2016; Sajid Umar et al., 2015; Sajid Umar, Rehman, et al., 2016). The study by (Sajid Umar et al., 2015) suggested that clinical signs in H9N2 infected birds showed improvement upon dietary supplementation with either Nigella sativa seeds and $\mathrm{TQ}$, or their combination. The study also reported a decline in clinical symptoms upon supplementation with $3 \%$ Nigella sativa seed; the antibody titre was also increased against H9N2 AIV, thereby improving immune response and suppressed viral pathogenicity in the treated turkeys when compared to $1 \%$ dietary supplementation. Subsequent studies confirmed this dose-dependent effect as a higher antibody titre was observed with $6 \%$ Nigella sativa dietary supplementation compared to $1 \%$ and $3 \%$ dietary supplementation (Sajid Umar, Munir, et al., 2016). These findings suggested that turkeys fed with Nigella sativa exhibited higher levels of cytokine gene expression, leading to increased antiviral behaviour and suppressed pathogenesis of H9N2 viruses. Another study showed that the combination of TQ and other herbs as a single supplement significantly reduced the clinical signs in turkeys fed with this combination; this was attributed to the TQ content of Nigella sativa which improved the immune response and reduced the viral pathogenicity in the treated birds (S. Umar et al., 2016). These findings concurred with previous studies that revealed enhanced immune response upon treatment with Nigella sativa extracts (Ahmad et al., 2013; Dorucu, Ispir, Colak, Altinterim, \& Celayir, 2009; Shewita \& Taha, 2011). Also, the study reported that TQ, when fed to turkeys infected with H9N2, showed a lower viral load and increased expression of Interferon-gamma (IFN $Y$ ) levels. It may suggest that TQ can stimulate and induce proliferation of cytotoxic T-cells to allow increased viral clearance.
Moreover, avian influenza virus subtype H5N1 has previously been reported to be treated with Nigella sativa extract. Ethanol extract of Nigella sativa showed moderate dose-dependent antiviral activity and prevented the replication of H5N1. Experimental works suggested that the inhibition may be mediated by increasing innate immunity (Dorra et al., 2019). However, another study found that Nigella sativa oil, when used as a vaccine adjuvant against $\mathrm{H} 5 \mathrm{~N} 1$, can exhibit a non-specific immunostimulant effect and induce cellular immune response that restricts the replication of H5N1 (Mady et al., 2013).

\section{Nigella sativa against plant viruses}

A few studies have reported the antiviral efficacy of Nigella sativa extracts against plant viral infections; some of the reported studies are as follows:

\section{Nigella sativa against Broad Bean Mosaic Virus}

Broad bean (Vicia faba L.) is one of the legumes affected by viruses globally (I. E. T. Mohamed \&, El Bushra El Sheikh El Nur, 2010). Broad Bean Mosaic Virus (BBMV) is a member of the Bromoviruses and is considered a common virus in fava bean fields. The antiviral activity of Nigella sativa has been tested against BBMV on Chenopodium amaranticolor plant as a local lesion host both in vitro and in vivo (E. F. Mohamed, 2011). The study proved that the extracts reduced the virus-induced local lesions and increased the in vitro inhibition percentages. On the other hand, the in vivo experiments found that pre-inoculation treatment inhibition was more effective in reducing virus pathogenicity compared to post-inoculation treatment. However, the crude extract achieved higher inhibition percentages compared to the dilutions possibly due to its richness in bioactive compounds (Schneider-Stock et al., 2014; Torequl Islam et al., 2016).

\section{Nigella sativa against Tobacco Mosaic Virus}

Tobacco Mosaic Virus (TMC) is another important plant virus that belongs to the genus Tobamovirus and is considered one of the top 10 plant viruses that cause significant economic losses in many crops (Scholthof et al., 2011). The antiviral activity of Nigella sativa extract has been evaluated on TMV in Nicotiana glutinosa and Datura metel as local lesion hosts of tobacco plants (El-Sayed, 2011). The results showed that 
the extract achieved complete recovery from virus infection by complete inhibition of the replication of the virus.

\section{Nigella sativa against Zucchini Yellow Mosaic Virus}

Besides BBMV and TMV, there are other pathogenic plant viruses, such as Zucchini Yellow Mosaic Virus (ZYMV); which is a member of the family Potyviridae. ZYMV causes a destructive worldwide epidemic in cucurbits. (Desbiez \& Lecoq, 1997). The antiviral activity of Nigella sativa decoction and infusion seeds extract has been examined against ZYMV infection in watermelon seedlings. The outcome of the study showed that Nigella sativa inhibited the progression of ZYMV infection both in vitro and in vivo; it did not just inhibit the clinical signs of virus infection but increased the plant growth parameters. The disease severity, percentage of infection, and viral load were correlated with the observed disease symptoms as well (Elbeshehy, 2017). This result agreed with another study by Abdel-Shafi S (2013) who found that the treatment of squash plants with aqueous Nigella sativa extract improved plant recovery from ZYMV infection and improved the plant growth parameters because Nigella sativa extract was able to induce plant resistance against ZYMV infection. Based on these findings, Nigella sativa extracts can be considered safe and recommendable for use as biological control of plant viruses.

\section{CONCLUSION}

The use of natural extracts and derivatives in disease prevention and cure has been on the increase globally due to their high tolerance and low side effects. Nigella sativa is a well-known plant used in folk medicine for many decades now; it is considered a "miracle herb" due to its effectiveness in managing several disease conditions. The available scientific data on Nigella sativa has revealed that Nigella sativa oil, extracts, and components, particularly thymoquinone, can serve as natural remedies for many diseases. Moreover, the extracts of Nigella sativa are proven to exhibit different medicinal properties even though their antiviral activity has not been fully exploited. This review focused on reviewing most of the published studies on the antiviral effects of Nigella sativa, especially those that demonstrated the antiviral activity of Nigella sativa and its bioactive compounds against the different plant, animal, and human viruses. Based on the outcome of the review, further studies are recommended for the development of Nigella sativa as a natural antiviral drug against various viruses. It is hoped that this review would be helpful to the interested researchers in the future, and will motivate further experiments (both in vitro, in vivo, and clinical trials) on the antiviral efficacy of Nigella sativa. This review has some limitations. One of them was the difficulty in finding the full texts of some published papers as only the abstract was published. Moreover, only English-language articles and no other language studies were included in this review.

\section{ACKNOWLEDGMENTS}

None.

\section{CONFLICT OF INTEREST}

The authors declare that there is no conflict of interest.

\section{AUTHORS' CONTRIBUTION}

All authors listed have made a contribution to the work, and approved the final manuscript for publication.

\section{FUNDING}

None.

\section{DATA AVAILABILITY}

Not applicable.

\section{ETHICS STATEMENT}

Not applicable.

\section{REFERENCES}

1. Abdel-Moneim A, Morsy BM, Mahmoud AM, Abo-Seif MA, Zanaty MI. Beneficial therapeutic effects of Nigella sativa and/or Zingiber officina in HCV patients in Egypt. EXCLI Journal. 2013;12(LC):943-955.

2. Abdel-Shafi S. Preliminary Studies on Antibacterial and Antiviral Activities of Five Medicinal Plants. Journal of Plant Pathology \& Microbiology. 2013;04(07):1-8. doi: 10.4172/2157-7471.1000190

3. Adam GO, Rahman MM, Lee SJ, et al. Hepatoprotective effects of Nigella sativa seed extract against acetaminophen-induced oxidative stress. Asian Pacific Journal of Tropical Medicine. 2016;9(3):221-227. doi: 10.1016/j.apjtm.2016.01.039 
4. Agha Q, Ahmad S, Islam M, Gill A, Athar M. Growth and production potential of five medicinal crops in highlands of Balochistan, Pakistan. Journal of Medicinal Plants Research. 2010;4(20):2159-2163.

5. Ahmad A, Husain A, Mujeeb $M$, et al. A review on therapeutic potential of Nigella sativa: A miracle herb. Asian Pac J Trop Biomed. 2013;3(5):337-352. doi: 10.1016/S2221-1691(13)60075-1

6. Akhondian J, Kianifar H, Raoofziaee M, Moayedpour A, Toosi MB, Khajedaluee $M$. The effect of thymoquinone on intractable pediatric seizures (pilot study). Epilepsy Research. 2011;93(1):39-43. doi: 10.1016/j. eplepsyres.2010.10.010

7. Akhtar MS, Riffat S. Field trial of Saussurea lappa roots against nematodes and Nigella sativa seeds against cestodes in children. J Pak Med Assoc. 1991;41:185187.

8. Al-Awadi F, Fatania $\mathrm{H}$, Shamte $\mathrm{U}$. The effect of a plants mixture extract on liver gluconeogenesis in streptozotocin induced diabetic rats. Diabetes Research (Edinburgh, Scotland). 1991;18(4):163-168. [Accessed 30 March 2018] http://www.ncbi.nlm.nih. gov/pubmed/1842751

9. Al-Gaby AM. Amino acid composition and biological effects of supplementing broad bean and corn proteins with Nigella sativa (black cumin) cake protein Nahrung. 1998;42(5):290-294. [Accessed 9 July 2019] http://www.ncbi.nlm.nih.gov/pubmed/9882224. doi: 10.1002/(SICI)1521-3803(199810)42:05<290::AIDFOOD290>3.0.CO;2-Y

10. Ali Sangi SM, Bawadekji A, Al Ali M. Comparative effects of metformin, Pleurotus ostreatus, Nigella sativa and Zingiber officinale on the streptozotocin-induced diabetes mellitus in rats. Pharmacognosy Magazine. 2018;14:S268-73. doi: 10.4103/pm.pm_108_18

11. Alkharfy KM, Ahmad A, Khan RMA, Al-Shagha WM. Pharmacokinetic plasma behaviors of intravenous and oral bioavailability of thymoquinone in a rabbit model. Eur J Drug Metab Pharmacokinet. 2015;40(3):319-323. doi: 10.1007/s13318-014-0207-8

12. Amin B, Hosseinzadeh H. Black cumin (Nigella sativa) and its active constituent, thymoquinone: An overview on the analgesic and anti-inflammatory effects. Planta Med. 2016;82(1-2):8-16. doi:10.1055/s-0035-1557838

13. Aqil K, Khan MUR, Aslam A, et al. Patho-biological studies of ppr virus in experimentally infected goats with reference to immunomodulatory activity of Nigella sativa seeds. Journal of Animal and Plant Sciences. 2017;27(6):474-484.

14. Aqil K, Khan M-R, Aslam A, et al. In vitro antiviral activity of Nigella sativa against Peste des petits ruminants (PPR) Virus. Zool Soc Pakistan. 2018;50(6):2223-2228.

15. Asif HM, Akhtar N, Iqbal A, et al. Nigella sativa: Monograph. Journal of Pharmacognosy and Phytochemistry (JPP). 2015;4(44):103-106.

16. Balamurugan V, Hemadri D, Gajendragad MR, Singh RK Rahman H. Diagnosis and control of peste des petits ruminants: a comprehensive review. VirusDisease. 2014;25(1):39-56. doi: 10.1007/s13337-013-0188-2

17. Banerjee $S$, Kaseb AO, Wang Z, et al. Antitumor activity of gemcitabine and oxaliplatin is augmented by thymoquinone in pancreatic cancer. Cancer Research. 2009;69(13):5575-5583. doi: 10.1158/0008-5472. CAN-08-4235

18. Barakat EMF, El Wakeel LM, Hagag RS. Effects of Nigella sativa on outcome of hepatitis C in Egypt. World J Gastroenterol. 2013;19(16):2529-2536. doi: 10.3748/ wjg.v19.i16.2529

19. Benencia F, Courreges MC. Antiviral activity of sandalwood oil against herpes simplex viruses-1 and -2. Phytomedicine: International Journal of Phytotherapy and Phytopharmacology. 1999;6(2):119123. doi: 10.1016/S0944-7113(99)80046-4

20. Blumel J, Burger R, Drosten $\mathrm{C}$, et al. Influenza virus. Transfusion Medicine and Hemotherapy. 2009;36(1):32-39. doi: 10.1159/000197314

21. Cattoli G, Susta L, Terregino C, Brown C. Newcastle disease: A review of field recognition and current methods of laboratory detection. J Vet Diagn Inve. 2011;23(4):637-656. doi: 10.1177/1040638711407887

22. Chaieb K, Kouidhi B, Jrah H, Mahdouani K, Bakhrouf A. Antibacterial activity of thymoquinone, an active principle of Nigella sativa and its potency to prevent bacterial biofilm formation. BMC Complement Altern Med. 2011;11(1):29. doi: 10.1186/1472-6882-11-29

23. Chen C, Zuckerman DM, Brantley S, et al. Sambucus nigra extracts inhibit infectious bronchitis virus at an early point during replication. BMC Vet Res. 2014;10(24). doi: 10.1186/1746-6148-10-24

24. Chen $N$, Zhou M, Dong $X$, et al. Epidemiological and clinical characteristics of 99 cases of 2019 novel coronavirus pneumonia in Wuhan, China: a descriptive study. The Lancet. 2020;395(10223):507-513. doi: 10.1016/S0140-6736(20)30211-7

25. De Clercq E. Antiviral drugs in current clinical use. J Clin Virol. 2004;30(2):115-133. doi: 10.1016/j. jcv.2004.02.009

26. Desbiez $\mathrm{C}$, Lecoq H. Zucchini yellow mosaic virus. Plant Pathology. 1997:46(6) 809-829. doi: 10.1046/j.13653059.1997.d01-87.x

27. Neamat H. Dorra, Mohamed A. EL-Barrawy, Shaimaa M. Sallam RSM. Evaluation of antiviral and antioxidant activity of selected herbal extracts. Journal of High Institute of Public Health. 2019;49(1):36-40. doi:10.21608/jhiph.2019.29464

28. Dorucu M, Ispir U, Colak S, Altinterim B, Celayir Y. The The effect of black cumin seeds, Nigella sativa, on the immune response of rainbow trout, oncorhynchus mykiss. Mediterranean Aquaculture Journal. 2009;2(1):27-33. doi: 10.21608/maj.2009.2667

29. Durrani FR, Chand N, Zaka K, Sultan A, Khattak FM, Durrani Z. Effect of different levels of feed added black seed (Nigella sativa L.) on the performance of broiler chicks. Pakistan Journal of Biological Sciences. 2007:10(22) 4164-4167. doi: 10.3923/ pjbs.2007.4164.4167

30. Eccles R. Understanding the symptoms of the common cold and influenza. Lancet Infect Dis. 2005;5(11):718725. doi: 10.1016/S1473-3099(05)70270-X

31. El-Sayed MSS. Chemical studies on constituents of some antiviral plant extracts. 2011. [Accessed 10 July 2019]. http://agris.fao.org/agris-search/search. 


\section{do?recordID=EG2012000758}

32. Elbeshehy EKF. Inhibitor activity of different medicinal plants extracts from Thuja orientalis, Nigella sativa $L$., Azadirachta indica and Bougainvillea spectabilis against Zucchini yellow mosaic virus (ZYMV) infecting Citrullus lanatus. Biotechnol Biotechnol Equip. 2017;31(2):270279. doi: $10.1080 / 13102818.2017 .1279572$

33. Elfadil H, Fahal A, Kloezen W, Ahmed EM, van de Sande $W$. The in vitro antifungal activity of Sudanese medicinal plants against Madurella mycetomatis, the eumycetoma major causative agent. PLoS Neglected Tropical Diseases. 2015;9(3):e0003488. doi: 10.1371/ journal.pntd. 0003488

34. Farnsworth NR, Akerele O, Bingel AS, Soejarto DD, Guo Z. Medicinal plants in therapy. Bulletin of the World Health Organization. 1985;63(6):965-981. doi: 10.1016/0378-8741(87)90016-X

35. Bafghi AF, Vahidi AR, Anvari MH, Barzegar K Ghafourzadeh $M$. The in vivo antileishmanial activity of alcoholic extract from Nigella sativa seeds. Afr J Microbiol Res. 2011;5(12):1504-1510. doi: 10.5897/ AJMR11.009

36. Geller C, Varbanov M, Duval RE. Human coronaviruses: Insights into environmental resistance and its influence on the development of new antiseptic strategies. Viruses. 2012;4(11):3044-3068. doi: 10.3390/ v4113044

37. Goreja WG. Black seed: nature's miracle remedy. Amazing Herbs Press. 2003.

38. Goyal SN, Prajapati C P, Gore PR, et al. Therapeutic potential and pharmaceutical development of thymoquinone: A multitargeted molecule of natural origin. Front Pharmacol. 2017;8:1-19. doi: 10.3389/ fphar.2017.00656

39. Griffin B, Citkovitz C. Survey: preferences and limitations of herbal medicine use among patients at a community acupuncture clinic. Medical Acupuncture, 2017;29(1):25-29. doi: 10.1089/acu.2016.1204

40. Hajarizadeh B, Grebely J, Dore GJ. Epidemiology and natural history of HCV infection. Nat Rev Gastroenterol Hepatol. 2013:10:553-562. doi: 10.1038/nrgastro.2013.107

41. Hajhashemi V, Ghannadi A, Jafarabadi H. Black cumin seed essential oil, as a potent analgesic and antiinflammatory drug. Phytother Res. 2004;18(3):195199. doi: 10.1002/ptr.1390

42. Halawani E. Antibacterial activity of thymoquinone and thymohydroquinone of Nigella sativa $\mathrm{L}$. and their interaction with some antibiotics. Adv Biol Res. 2009;3(5-6):148-152.

43. Houghton PJ, Zarka R, Heras BDL, Hoult JR. Fixed oils of Nigella sativa and derived thymoquinone inhibit eicosaniod generation in leukocytes and membrane lipid peroxidation. Planta Med. 1995;61(6):33-36.

44. Ibrahim F, Asghar MA, Iqbal J, Ahmed A, Khan AB. Inhibitory effects of natural spices extracts on Aspergillus growth and aflatoxin synthesis. Australian Journal of Crop Science. 2017;11(12):1553-1558. doi: 10.21475/ajcs.17.11.12.pne709

45. Kahn JS, McIntosh K. History and recent advances in coronavirus discovery. Pediatr Infect Dis J.
2005;24(11 SUPPL.):S223-S227. doi: 10.1097/01. inf.0000188166.17324.60

46. Kalamegam G, Alfakeeh SM, Bahmaid AO, et al. In vitro evaluation of the anti-inflammatory effects of thymoquinone in osteoarthritis and in silico analysis of inter-related pathways in age-related degenerative diseases. Frontiers in Cell and Developmental Biology. 2020;8:1-12. doi: 10.3389/fcell.2020.00646

47. Khan AU, Tipu MY, Shafee M, et al. In-ovo antiviral effect of Nigella sativa extract against newcastle disease virus in experimentally infected chicken embryonated eggs. Pak Vet J. 2018;38(4):434-437. doi: 10.29261/pakvetj/2018.075

48. Khan SH, Anjum MA, Parveen A, Khawaja T, Ashraf NM. Effects of black cumin seed (Nigella sativa L.) on performance and immune system in newly evolved crossbred laying hens. VET Q. 2013;33(1):13-19. doi: 10.1080/01652176.2013.782119

49. Khazdair MR. The protective effects of Nigella sativa and its constituents on induced neurotoxicity. J Toxicol. 2015;2015. doi: 10.1155/2015/841823

50. Kitazato K, Wang $\mathrm{Y}$, Kobayashi N. Viral infectious disease and natural products with antiviral activity. Drug Discoveries \& Therapeutics. 2007;1(1):14-22. [Accessed 11 July 2019]. http://www.ncbi.nlm.nih. gov/pubmed/22504360

51. Kumar P, Patra AK. Beneficial uses of black cumin (Nigella sativa L.) seeds as a feed additive in poultry nutrition. Worlds Poult Sci J. 2017;73(4):872-885. doi: 10.1017/S0043933917000848

52. Lin LT, Hsu WC, Lin CC. Antiviral natural products and herbal medicines. J Tradit Complement Med. 2014;4(1):24-35. doi: 10.4103/2225-4110.124335

53. Looker KJ, Magaret AS, May MT, et al. Global and regional estimates of prevalent and incident herpes simplex virus type 1 infections in 2012. PLOS ONE. 2015;10(10):1-17. doi: 10.1371/journal.pone.0140765

54. Mady WH, Arafa A, Hussein AS, Aly MM, Madbouly HM. Nigella sativa oil as an immunostimulant adjuvant in $\mathrm{H} 5$ based DNA vaccine of H5N1 avian influenza virus. Glob Vet. 2013;10(6):663-668. doi: 10.5829/idosi. gv.2013.10.6.73101

55. Fehr A.R, Perlman S. Coronaviruses: An overview of their replication and pathogenesis. In: Maier HJ, Bickerton E, Britton P, eds. Coronaviruses: Methods and Protocols. Humana Press, New York, NY; 2015;1282:1- 23. doi:10.1007/978-1-4939-2438-7_1

56. Marty AM, Jones MK. The novel coronavirus (SARS-CoV-2) is a one health issue. One Health. 2020:9;100123.doi: 10.1016/j.onehlt.2020.100123

57. Meral I, Yener Z, Kahraman T, Mert N. Effect of Nigella sativa on glucose concentration, lipid peroxidation, anti-oxidant defence system and liver damage in experimentally-induced diabetic rabbits. Journal of Veterinary Medicine Series A: Physiology Pathology Clinical Medicine. 2001;48(10):593-599. doi: 10.1046/j.1439-0442.2001.00393.x

58. Mohamed A, Abdul M, Alobaidi AHA. Evaluation of therapeutic efficacy of Nigella sativa (black seed) for treatment of allergic rhinitis. Allergic Rhinitis. 2012; doi: $10.5772 / 26946$ 
59. Mohamed EF. Inhibition of Broad bean mosaic virus (BBMV) using extracts of Nigella (Nigella sativa L.) and Zizyphus (Zizyphus spina-christi Mill .) plants. Journal of American Science. 2011;7(12):727-734.

60. Mohamed IET, Nur EBESE, Abdelrahman MEN. The antibacterial, antiviral activities and phytochemical screening of some Sudanese medicinal plants. EurAsian Journal of BioSciences. 2010;16(4):8-16.

61. Mohammed NK, Hussin ASM, Tan CP, Abdul MYM, Alhelli, AM. Quality changes of microencapsulated Nigella sativa oil upon accelerated storage. International Journal of Food Properties. 2018;20(3):S2395-S2408. doi: 10.1080/10942912.2017.1371189

62. Mohideen S, llavarasan R, Sasikala E, Kumaran RT. Hepatoprotective activity of Nigella sativa Linn. Indian Journal of Pharmaceutical Sciences. 2003;65(5):550551.

63. Mohtashami R, Huseini HF, Heydari M, et al. Efficacy and safety of honey based formulation of Nigella sativa seed oil in functional dyspepsia: A double blind randomized controlled clinical trial. J Ethnopharmacol. 2015;175:147-152. doi: 10.1016/j.jep.2015.09.022

64. Nakagawa K, Lokugamage KG, Makino S. Viral and cellular mRNA translation in coronavirus-infected cells. In: Advances in virus research. Advances in Virus Research. 2016;96:165-192. Academic Press. doi: 10.1016/bs.aivir.2016.08.001

65. Onifade AA, Jewell AP, Ajadi TA, Rahamon SK, Ogunrin OO. Effectiveness of a herbal remedy in six HIV patients in Nigeria. Journal of Herbal Medicine. 2013;3(3):99103. doi: 10.1016/j.hermed.2013.04.006

66. Onifade A, Jewel A, Okesin A, et al. The phytochemistry and safety of a-Zam, herbal remedy used for treatment of HIV infection in Nigeria. Tropical Journal of Health Sciences. 2011;18(1):40-45. doi: 10.4314/tjhc. v18i1.64485

67. Onifade A, Jewell A. 5-Month herbal therapy and complete sero-reversion with recovery in an adult HIV/ AIDS patient. Journal of Antivirals \& Antiretrovirals. 2012;01(S1):124. doi: 10.4172/scientificreports.124

68. Onifade AA, Jewell AP, Okesina AB. Virologic and immunologic outcome of treatment of HIV infection with a herbal concoction, A-zam, among clients seeking herbal remedy in Nigeria. African Journal of Traditional, Complementary and Alternative Medicines. 2011;8(1):37-44. doi: 10.1625/jcam.8.37

69. Onifade AA, Jewell AP, Okesina AB. Seronegative Conversion of an HIV Positive Subject Treated with Nigella sativa and Honey. African Journal of Infectious Diseases. 2015;9(2):47-50. doi: 10.4314/ajid.v9i2.6

70. Onifade AA, Jewell AP, Adedeji AW. Nigella sativa concoction induced sustained seroreversion in HIV patient. African Journal of Traditional, Complementary, and Alternative Medicines: AJTCAM / African Networks on Ethnomedicines. 2013;10(5):332-335. doi: 10.4314/ajtcam.v10i5.18

71. Onifade AA, Jewell AP. Does Nigella sativa concoction cured HIV infection? The Journal of Infectious Diseases. Photon. 2014;113:264-269.

72. Ou S-C, Giambrone JJ. Infectious laryngotracheitis virus in chickens. World Journal of Virology. 2012;1(5):142149. doi: 10.5501/wjv.v1.i5.142
73. Oyero OG, Toyama M, Mitsuhiro N, et al. Selective inhibition of hepatitis $C$ virus replication by Alpha-Zam, A Nigella sativa seed formulation. African Journal of Traditional, Complementary, and Alternative Medicines : AJTCAM. 2016;13(6):144-148. doi: 10.21010/ajtcam.v13i6.20

74. Peng L, Liu A, Shen $Y$, et al. Antitumor and anti-angiogenesis effects of thymoquinone on osteosarcoma through the NF-KB pathway. Oncology Reports. 2013:571-578. doi: 10.3892/or.2012.2165

75. Randhawa MA, Alghamdi MS. Anticancer activity of Nigella sativa (black seed) - A review. Am J Chin Med. 2011;39(06):1075-1091. doi: 10.1142/ S0192415X1100941X

76. Randhawa M, Alenazy A, Alrowaili M, Basha J. An active principle of Nigella sativa L, thymoquinone, showed significant antimicrobial activity against anaerobic bacteria. J Intercult Ethnopharmacol. 2016;6(1):97101. doi: $10.5455 /$ jice.20161018021238

77. Rezazadeh F, Moshaverinia M, Motamedifar M, Alyaseri M. Assessment of Anti HSV-1 Activity of aloe vera gel extract: an in vitro study. J Dent (Shīrāz, Iran). 2016;17(1):49-54. [Accessed 15 March 2019]. http://www.ncbi.nlm.nih.gov/ pubmed/26966709\%5Cnhttp://www.pubmedcentral. nih.gov/articlerender.fcgi?artid=PMC4771053

78. Rizka A, Setiati S, Lydia A, Dewiasty E. Effect of Nigella sativa seed extract for hypertension in elderly: a double-blind, randomized controlled trial. Acta Medica Indonesiana. 2017;49(4):307-313.

79. Salem ML, Hossain MS. Protective effect of black seed oil from Nigella sativa against murine cytomegalovirus infection. International Journal of Immunopharmacology. 2000;22(9):729-740. doi: 10.1016/S0192-0561(00)00036-9

80. Salem ML. Immunomodulatory and therapeutic properties of the Nigella sativa. seed. Int Immunopharmacol. 2005;5(13-14);1749-1770. doi: 10.1016/j.intimp.2005.06.008

81. Schneider-Stock R, Fakhoury IH, Zaki AM, El-Baba CO, Gali-Muhtasib HU. Thymoquinone: Fifty years of success in the battle against cancer models. Drug Discovery Today. 2014;19(1):18-30. doi: 10.1016/j. drudis.2013.08.021

82. Scholthof KBG, Adkins S, Czosnek H, et al. Top 10 plant viruses in molecular plant pathology. Molecular Plant Pathology. Wiley-Blackwell. 2011:12(9)938-954. doi: 10.1111/j.1364-3703.2011.00752.x

83. Seifried $O$. Histopathology of infectious laryngotracheitis in chickens. Journal of Experimental Medicine. 1931;54(6):817-826. doi: 10.1084/jem.54.6.817

84. Shewita RS, Taha AE. Effect of dietary supplementation of different levels of black seed (Nigella sativa) on growth performance, immunological, hematological and carcass parameters of broiler chicks. World Academy of Science, Engineering and Technology. 2011;5(5):788-794.

85. Sökmen A. Antiviral and cytotoxic activities of extracts from the cell cultures and respective parts of some Turkish medicinal plants. Turk J Biol. 2001;25:343-350.

86. Shekhar TC, Anju G. A comprehensive review on Ageratum conyzoides linn. (goat weed). International 
Journal of Pharmaceutical and Phytopharmacological Research 2012;1(6):391-395.

87. Toghyani M, Toghyani M, Gheisari A, Ghalamkari G, Mohammadrezaei M. Growth performance, serum biochemistry and blood hematology of broiler chicks fed different levels of black seed (Nigella sativa) and peppermint (Mentha piperita). Livestock Science. 2010;129(1-3):173-178. doi: 10.1016/j. livsci.2010.01.021

88. Tollba AAH. Using some natural additives to improve physiological and productive performance of broiler chicks under high temperature conditions. 1 - Thyme (Thymus vulgaris L.) or fennel (Foeniculum vulgare L.). Egyptian Poultry Science Journal. 2003;23(2):313-326.

89. Islam MT, Sultana N, Riaz TA, et al. Thymoquinone is knocking at the door of clinical trial. Int Arch Med. 2016;9(122)1-25. doi: 10.3823/1993

90. Trilla A, Trilla G, Daer C. The 1918 "Spanish Flu" in Spain. Clin Infect Dis. 2008a;47(5):668-673. doi: 10.1086/590567

91. Ulasli M, Gurses SA, Bayraktar R, et al. The effects of Nigella sativa (Ns), Anthemis hyalina (Ah) and Citrus sinensis (Cs) extracts on the replication of coronavirus and the expression of TRP genes family. Molecular Biology Reports. 2014;41(3):1703-1711. doi: 10.1007/ s11033-014-3019-7

92. Umar S, Shah MAA, Munir MT, et al. Synergistic effects of thymoquinone and curcumin on immune response and anti-viral activity against avian influenza virus (H9N2) in turkeys. Poult Sci. 2016;95(7):1513-1520. doi: 10.3382/ps/pew069

93. Sajid U, Munir MT, Subhan S, et al. Protective and antiviral activities of Nigella sativa against avian influenza (H9N2) in turkeys. Journal of the Saudi Society of Agricultural Sciences. 2016. doi: 10.1016/j. jssas.2016.09.004

94. Sajid U, Rehman A, Younus M, et al. Effects of Nigella sativa on immune responses and pathogenesis of avian influenza (H9N2) virus in turkeys. J Appl Poult Res. 2016;25(1):95-103. doi: 10.3382/japr/pfv070

95. UNAIDS. 2006 Report on the global AIDS epidemic. Joint UN Programme on HIV/AIDS, UNAIDS/06. 2006. [Accessed 25 March 2020]. http://data.unaids. org/pub/report/2006/2006_gr_en.pdf\%0Ahttp:// data.unaids.org/pub/report/2006/2006_gr_ en.pdf\%0Awww.unaids.org.

96. Van Lint AL, Knipe DM. Herpesviruses. Encyclopedia of Microbiology. 2019;565-579. University of Texas Medical Branch at Galveston. doi: 10.1016/B978-012-801238-3.02509-5

97. Vermani K, Garg S. Herbal medicines for sexually transmitted diseases and AIDS. Journal of Ethnopharmacology. 2002;80(1):49-66. doi: 10.1016/ S0378-8741(02)00009-0

98. Wang H, Ooi EV, Ang PO. Antiviral activities of extracts from Hong Kong seaweeds. Journal of Zhejiang University SCIENCE B. 2008;9(12), 969-976. doi: 10.1631/jzus.B0820154

99. Wang W, Wang SX, Guan HS. The antiviral activities and mechanisms of marine polysaccharides: an overview.
Mar Drugs. 2012;10(12):2795-2816. doi: 10.3390/ md10122795

100. Weiss SR, Navas-Martin S. Coronavirus pathogenesis and the emerging pathogen severe acute respiratory syndrome coronavirus. Microbiol Mol Biol Rev. 2005;69(4):635-664. doi: 10.1128/mmbr.69.4.635664.2005

101. Woo CC, Kumar AP, Sethi G, Tan KHB. Thymoquinone: Potential cure for inflammatory disorders and cancer. Biochem Pharmacol. 2012;83(4):443-451. doi: 10.1016/j.bcp.2011.09.029

102. World Health Organization. Global hepatitis report, 2017. Global Hepatitis Programme. WHO. 2017a. [Accessed 25 March 2020]. https://apps.who.int/iris/ bitstream/handle/10665/255016/9789241565455eng. pdf? sequence $=1$ \&isAllowed $=y$

103. World Health Organization. Smallpox. 2017b. [Accessed 25 April 2018] http://web.archive. org/web/20071017184119/http://who.int:80/ mediacentre/factsheets/smallpox/en/print.html

104. World Health Organization (WHO). 2019. HIV/AIDS. [Accessed 30 April 2020]. https://www.who.int/newsroom/fact-sheets/detail/hiv-aids

105. Wosu LO. Management of clinical cases of peste des petits ruminants (PPR) disease in goats. Beitr Trop Landwirtsch Veterinarmed. 1989;27(3):357-361. [Accessed 12 April 2019] http://www.ncbi.nlm.nih. gov/pubmed/2619704

106. Yaseen SA. Potential antiviral activity of Nigella sativa extract. Iraqi Journal of Veterinary Sciences. 2003;17(1):37-40. [Accessed 12 April 12, 2019]. https:// eurekamag.com/research/004/276/004276713.php

107. Yimer EM, Tuem KB, Karim A, Ur-Rehman N, Anwar F. Nigella sativa $L$. (Black Cumin): A promising natural remedy for wide range of illnesses. Evidence-Based Complementary and Alternative Medicine. 2019. doi: 10.1155/2019/1528635

108. Zaher KS, Ahmed WM, Zerizer SN. Observations on the biological effects of black cumin seed (Nigella sativa) and green tea (Camellia sinensis ). Global Veterinaria. 2008;2(4):198-204.

109. Dogar MZUH, Adnan H, Akhtar MS, Sheikh MA. Preliminary Assessment of Efficacy of Nigella sativa Seeds In Acute Lymphoblastic Leukemia In Local Children. Pharmacologyonline. 2009;2:769-777.

110. Zaoui A, Cherrah Y, Alaoui K, Mahassine N, Amarouch $\mathrm{H}$, Hassar M. Effects of Nigella sativa fixed oil on blood homeostasis in rat. J Ethnopharmacol. 2002;79(1):2326. doi: 10.1016/S0378-8741(01)00342-7

111. Zihlif MA, Mahmoud IS, Ghanim MT, et al. Thymoquinone efficiently inhibits the survival of EBV-infected B cells and alters EBV gene expression. Integrative Cancer Therapies. 2013;12(3):257-263. doi: $10.1177 / 1534735412458827$

112. Zohary D, Hopf M, Weiss E. Domestication of plants in the Old World: the origin and spread of domesticated plants in Southwest Asia, Europe, and the Mediterranean Basin. 2012. Oxford University Press. doi: 10.1093/acprof:osobl/9780199549061.001.0001 